\title{
Navigating borders: The evolution of the Cass Clay Food Partners
}

\author{
Special JAFSCD Issue \\ Local Government in Food Systems Work \\ Snonsored bv \\ GROWING FOOD
}

Abby Gold a*

North Dakota State University

Noelle Harden b

University of Minnesota Extension

Submitted D ecember 8, 2017 / Revised April 11 and June 12, 2018 / Accepted June 12, 2018 /

Published online O ctober 17, 2018

Citation: Gold, A., \& Harden, N. (2018). Navigating borders: The evolution of the Cass Clay Food Partners. Journal of A griculture, Food Systems, and C ommunity D evelopment, 8(Suppl. 2), 29-38. https:/ / doi.org/ 10.5304/ jafscd.2018.08B.010

Copyright (๔ 2018 by the Authors. Published by the Lyson Center for Civic Agriculture and Food Systems. Open access under CC BY license.

\begin{abstract}
The Cass Clay Food Partners is an integrated food network serving Cass County, North D akota, and Clay County, Minnesota, through the combined work of a food policy council, action network, and steering committee. In this paper, we describe the evolution of the network from project-based work to policy development to a partnership that integrates both programs and policy for greater impact. We also highlight the many types of boundaries the network has navigated in order to attain success in advancing alternative food systems for the Red River Valley community. These boundaries include

\footnotetext{
a * Corresponding author: Abby Gold, PhD , MPH, RD, vice chair and associate professor, D epartment of Public Health, North Dakota State University; D ept. 2662, P.O. Box 6050; Fargo, ND 58108-6050 USA; +1-701-231-7478; abby.gold@ndsu.edu

b Noelle Harden, MS, Health and Nutrition Educator, University of Minnesota Extension; 715 11th St North; Moorhead,
} MN 56560 USA; +1-218-280-5253; harde073@umn.edu
\end{abstract}

political borders such as the state line between North Dakota and Minnesota, as well as philosophical divisions between stakeholders and decision-makers. Lastly, we highlight the pitfalls faced and lessons learned by the network during this process.

\section{Keywords}

Food Policy Council, Food Network, Policy Blueprints, Food System Planning, Food Access

\section{Dedication}

Gina Nolte, our friend and colleague, passed away after a courageous battle with cancer while we were writing this paper. Gina was a founding member of the Cass Clay Food Systems Initiative who used her boundless energy as a successful and effective proponent for public health and systems changes. G ina will be sorely missed in our small public health community. This paper is dedicated to $\mathrm{G}$ ina, as it could not have been written without her leadership. 


\section{Introduction}

Like many communities, the Red River Valley region of Cass County, North Dakota, and Clay County, Minnesota, is on a path to intentionally create a healthier and vibrant food system. The journey down this path is being led, in part, by a network of food system professionals and community members currently known as Cass Clay Food Partners (CCFP). The network first formed in 2010 out of a recognition that, despite being widely cited as an agricultural mecca, the Red River Valley has substantial room for improvement when it comes to systemic challenges such as food insecurity, dietrelated chronic disease, and lack of equitable access to healthy, culturally appropriate, and sustainably sourced food (Fargo-Moorhead Metropolitan Council of G overnments, 2013). This region is often recognized by its boundaries, including its namesake, the Red River that forms the border between the two states. The persistence of political, social, and economic boundaries complicate food systems change, but there can be great success when bridges are built across these divides. In this essay, we seek to unpack those boundaries as we tell the story of the CCFP.

As two core members of the CCFP and public health nutrition scholars, we are sharing our perspective in order to help other food networks and food policy councils build the bridges necessary to move alternative food systems from idea to reality. We have found this is best achieved through strengthening connections between community leaders, local elected officials, food system and urban planning professionals, and the public. In this essay, we reflect on the unique organizational evolution of the CCFP from initiative to commission to partnership, highlighting the role that the place-based network has played in building leadership capacity among food system stakeholders and in supporting the implementation of a formal food systems plan and associated policy blueprints. We propose that the evolution of the CCFP demonstrates how a comprehensive food network (which includes a food policy council) can effectively navigate a variety of boundaries in order to advance systemic change at the local, regional, and state level.

The political boundary between Cass County,
North D akota, and Clay County, Minnesota, creates an underlying tension between the cultural support for alternative food systems and the economic support for the industrial and conventional commodity-based food system in the heart of the Red River Valley. We draw on our experiences as members of the CCFP Steering Committee, as well as objective interviews and surveys conducted with members of the network, to describe the tension. Building on the literature related to food networks and local food policy, we describe the evolution of CCFP and highlight key lessons learned along the way. Lastly, we explain why we think making changes to the food system is inhibited by the prevailing tensions around navigating boundaries.

\section{Food Policy Councils and the Democratic Process}

Colasanti, Wright, and Reau (2009) suggest a democratic process in food systems can be achieved through a leaderful framework to catalyze community change. They define a leaderful framework as the facilitation of a process that is conducted through an unbiased, minimally influential manner and focused on "co-discovery" where knowledge becomes the province of all involved, not just the experts. Another aspect of this process includes team leadership, which creates and implements strategic action plans that then incorporate mutual respect around varying value systems (e.g., organic vs. conventional agriculture). This approach is nonprescriptive, which is especially important in cases like the Red River Valley where value systems conflict. Community change is derived through deliberate decision-making built on trust and transparency. In sum, diverse, regional collaboration promotes a functional local food system through policy alignment at all levels of government (Wegener, Seasons, \& Raine, 2013).

Food policy councils can promote local food systems through the notion of civic agriculture (Andreatta, Rhyne, \& Dery, 2008; Lyson, 2004). For example, food policy councils can advocate for access to community supported agriculture operations (CSAs) by low-income and food-insecure households, and foster social networks between farmers, volunteers, low-income households, and other community members. Direct contact 
between farmers and consumers may enhance selfreliance among low-income participants by building food literacy and forging community connections.

In the context of local government, food systems work takes a "back seat" to other planning issues, such as housing, transportation, and the environment (Pothukuchi \& Kaufman, 1999), further exacerbating the barrier between citizens and farmers. Because of the relegation of food systems to a lesser position in municipal planning, issues such as the loss of farmland around cities and lack of food access in neighborhoods go unnoticed until a food-justice crisis point is reached (Walker, Keane, \& Burke, 2010). Incorporating food and farming principles into municipal planning often serves to focus decision-makers on systemic changes around food insecurity and limited access to healthy foods for specific populations (Clark, Freedgood, Irish, Hodgson, \& Raja, 2017; Horst, 2017). Sonnino, Marsden, and Moragues-Faus (2016) recommend a place-based approach to solving food insecurity because it "offers the conceptual advantage of building far more complexity and diversity into generalized and aggregated food security debates: it is a stage for more reflexive food governance" (p. 487). Food policy networks can affect change by unifying fragmented approaches and creating networks that pressure various sectors to work together to solve multifactorial problems like food insecurity with complementary solutions (Sadler, Arku, \& Gilliland, 2015).

Expanding access to healthy food within the community improves health behaviors as well as addresses issues of food insecurity (Sonnino et al., 2016; Walker et al., 2010). Consensus-making and citizen conferences with policymakers are increasingly common methods for engaging the community around food systems changes and increasing access to healthy food for all citizens (Ankeny, 2016). However, little consensus exists on the role of the public's participation in food policy creation (Ankeny, 2016; Pothukuchi \& Kaufman, 1999; Schiff, 2008). Some argue that the push for food policy councils to focus on locally based ordinances is an attempt to move the responsibility of food planning from the state (or federal) government to often fiscally insolvent local municipalities (Sadler et al., 2015). Another perspective says that when people are engaged through local food policy councils in a reasoned, collective sense of good through a deliberative, democratic process, they can take back local control over food systems from the corporate-entrenched, big-food power structure (Ankeny, 2016). Accordingly, the CCFP's vision is to use a deliberative, democratic process to build a local food system that is safe, nutritious, affordable, and culturally based for all members of the community.

\section{Birth of a Local Food N etwork}

Bridges have played a prominent role in the development of the Red River Valley and also provide an apt metaphor for understanding the evolution of the Cass Clay Food Partners. The CCFP is a food network that has experienced multiple transformations to fulfill an evolving array of functions related to social connectedness, civic engagement in the food system, and community-driven change. The trajectory of this network offers some lessons to be shared in the context of a racially fragmented urban-rural interface where alternative food systems are beginning to blossom, but the commodity food system is very much ingrained. The network began in 2010 as the Cass Clay Food Systems Initiative (hereafter the Initiative) and is thriving today as the newly restructured CCFP. The Initiative was launched in 2010 by public health and Extension professionals in Clay County, Minnesota, and Cass County, North D akota.

The Initiative emerged in the context of two major state-level efforts in Minnesota related to increasing access to healthy food: the Statewide Health Improvement Partnership (SHIP) and the development of the Minnesota Food Charter (Minnesota Food Charter, n.d.-b). The SHIP program began in 2008 with state funding administered by the D epartment of Health to address chronic disease prevention through communitybased activities related to healthy eating, active living, and smoking cessation. The SHIP program has provided financial and other support to local health departments and emphasizes strategies that are evidence-based and that meet identified community needs. The Minnesota Food Charter (MFC) 
is a roadmap for food systems change that was launched in 2014 after an extensive public input process. Strategies in the MFC include explicit support for equitable local food system planning and for food policy councils at all levels of government. Both the SHIP program and the MFC have provided state-level support at critical times in the development of CCFP despite the lack of parallel programs in North D akota. This difference in funding and organizational support between the two states is one of several factors that complicate efforts to work across this political border.

The Initiative was launched through a local foods summit with over 100 participants and agricultural commissioners from both states. Through facilitated group activities, the summit identified five overarching topics of interest to participants, which then became the five task forces that composed the Initiative's early structure. Through the decentralized work of the task forces as well as an overarching steering committee, the Initiative effectively sponsored and branded several projects, mostly related to community gardens, home gardening, and networking events connecting growers and institutional food buyers.

D uring 2013 interviews with founding members of the Initiative, responses pointed to this project-based work as important early successes. One member described how it was important to engage in projects that "make a difference right away, so that we have some immediate success," especially since other members were "not ready for the bigger picture stuff" such as policy research, education, and advocacy. O ver time, however, the energy behind the task forces began to fade; even after they were consolidated from five to three topic areas, it was difficult to sustain the energy needed to maintain existing programs or to create new ones. Network leaders began to recognize that in order to achieve a broader vision of transforming food access through policy and other systemic changes, the network needed to evolve into a more formalized food policy council. A council would then have greater opportunity for direct influence on the democratic process by strengthening bridges between food systems professionals and policymakers. In order to get there, the network took what would prove to be a pivotal step on the journey: the development of the Metropolitan Food Systems Plan (Fargo-Moorhead Metropolitan Council of G overnments, 2013).

\section{Metropolitan Food Systems Plan}

Initiative leaders increasingly saw local and county planning efforts as an essential entry point into the realm of food policy. Core members of the Initiative drafted language and recommendations related to healthy food access and local food systems. These recommendations were then adopted in the Fargo Comprehensive Plan, which was approved in May 2012. After this initial milestone, Initiative leaders approached the Fargo-Moorhead Metropolitan Council of G overnments (MetroCOG), a quasigovernmental planning agency mainly tasked with transportation planning, and received official approval from the board to begin work on a local foods assessment report. At the end of 2013, the Metropolitan Food Systems Plan was finalized.

The planning document provided data and recommendations on the following key issues related to local food and healthy food access:

- Food insecurity, accessing local food shelves, SNAP participation, opportunities to increase local food consumption;

- Food access and emerging food deserts;

- Growth in the interest of local food;

- Market analysis and research regarding the local food system;

- Reducing barriers for institutions that want to incorporate local foods;

- Fostering cooperation and building a local food distribution network; and

- Recognition of the local food system by local governments for improved land use, zoning regulations, and community planning that supports access to healthy and local food.

The Metropolitan Food System Plan (2013) also included a critical recommendation to form an advisory commission tasked with consulting with local and elected county officials about food access and related issues. In early 2014, the leaders from the Initiative presented the plan to the four municipal and two county jurisdictions and 
received their approval. Throughout 2014, the leaders of the Initiative met regularly to deliberate on the next steps needed in order for the advisory commission to materialize and eventually obtained a Joint Powers Agreement between the city of Fargo and Clay County establishing the Cass Clay Food Systems Advisory Commission, which later became the Cass Clay Food Commission (hereafter Commission). At the end of 2014, they approached the six jurisdictions again to present the Joint Powers Agreement and request the appointment of one representative to serve a two-year term on the Commission. Both the MFC and the SHIP program were shown as examples to demonstrate what state-level support for and momentum around addressing food systems through local policy efforts looked like.

\section{Formation of the Commission}

The Commission is the first food policy council in the state of North Dakota and one of only three in Minnesota. As the first food policy council in Minnesota outside of the Twin Cities metro area, the Commission is an important symbol for the advancement of food policy work from urban to rural Minnesota. The goal of the Commission is to affect all levels of the community's food system to assure that residents of Cass and Clay counties have access to safe, nutritious, and affordable foods. Commission membership includes six city council members or county commissioners (one from each jurisdiction represented by the Commission) and five at-large members who were selected by the steering committee and voted for approval by the membership. At-large members represent various sectors of the local food system.

The first two years of work with the Commission led to a great deal of education, leadership development of Commission members, and increased connectivity between community members, key stakeholders, and elected officials. Ten policy blueprints were approved, published online, and broadly disseminated to planning departments in the two states (City of Fargo, n.d.). Blueprint topics were determined through a community engagement process, a survey of the commissioners, and with the expertise of the steering committee. To date, only one new policy has been enacted based on the recommendations in the blueprint: the adoption of a chicken ordinance in Fargo. Some of the factors contributing to the successful adoption of the chicken policy include significant public interest in the issue, increased pressure over time on the city of Fargo to take action, and the deliberate steps taken by network leaders to cultivate the buy-in of Fargo City Council members. A consultant assisted in this process by helping to develop a communications strategy for the short-term campaign, as well as helping to create a new vision and structure for the network.

After two years, we used a survey instrument to gauge commissioners' knowledge, interest, and readiness to present the blueprints focused on urban agriculture to their respective jurisdictions. In other words, we wondered if elected officials were ready to cross over from community education to intentional policy change. We developed and administered a brief retrospective pre/ post questionnaire at one of the commission meetings. Two of the steering committee members also conducted follow-up one-on-one interviews with all of the non-at-large commissioners $(\mathrm{n}=6)$. Survey results from the 9 commissioners present at the meeting indicated that (1) knowledge about urban agriculture went from no knowledge or slightly knowledgeable to knowledgeable, (2) their ranking of the importance of urban agriculture changed from slightly important to important or very important, and (3) their readiness to present the blueprints to jurisdictions was evenly distributed between not ready to ready. The most frequently cited blueprints that commissioners believed would resonate with their jurisdictions were related to community gardens, farmers markets, and cottage food laws. Commissioners steered away from the more controversial and innovative blueprints, such as municipal composting, backyard season extension, and backyard beekeeping.

As elucidated by these interviews, commissioners believed that (1) the blueprints were very valuable and should be shared with jurisdictions, (2) the education was critical and should continue, (3) the community should move from planning and education to action and implementation-driven by active community members and not 
commissioners- and (4) youth and minority groups must be engaged in the process.

In order to enhance community engagement as requested by the commissioners' feedback, the steering committee implemented a strategic communication process. The intent was to encourage community members to bring food policy- related issues to their jurisdictions so that commissioners were not acting alone when introducing the policy blueprints. In other words, more effort was needed to build bridges between the community and the Commission before any new policy changes, much like how the Fargo backyard chicken ordinance was brought forward by citizens and ultimately was passed by the Fargo City Council with advisory support from the Commission leaders within the steering committee. This decision was reinforced through meetings with food systems leaders (including the pioneer of the Minnesota Food Charter) from the Twin Cities Metro with more experience organizing food policy work.

\section{Strategic Communications Planning for Cass Clay Food Partners}

During the time the Metropolitan Food System

Plan was being written, the level of engagement between the network and the public was fairly high. Members of the community had multiple opportunities to provide input in the plan's development, to attend network-related events, and to join task forces. But starting in 2014, the network leaders devoted most of their time toward the launch of the Commission, relationship-building with Commission members, the design of bimonthly Commission meetings, and the development of policy blueprints. The project-based work of the Initiative consequently disappeared, and as a result, the network was less connected with the community.

At the same time the Initiative disappeared, new grassroots energy was fueling food systems change through the creation of social entrepreneurial endeavors such as the Red River Farmers Market, the Ugly Food of the North network that was addressing food waste issues, and the Little Free $\mathrm{G}$ ardens initiative. These projects included many of the same key players; in particular, the Commission's coordinator played a vital role in weaving together the projects and people involved in advancing community food systems change and discovering the potential collective impact of these interconnections. Concurrently, the Commission members were hearing from elected officials and city planners that in order to advance any policy, they would need community members applying pressure to local policy makers to take action on the issue identified in the policy blueprints. The concept of a new umbrella structure for the network-Cass Clay Food Partners (CCFP) - began to take root. This new structure would bridge the policy work of the Commission with the grassroots organizing happening throughout the community.

A subcommittee met with a consultant for nine months in late 2016 and 2017 to formulate CCFP's updated vision: an overarching network structure including the Commission, the steering committee (comprising core network leaders from the original founding organizations), and a new component: the Cass Clay Food Action Network. This process enabled CCFP to develop strategic language and tactics to engage a broad swathe of the community and to appeal to the cultural and political nuances of each jurisdiction. The purpose of the Action Network is to revive some of the grassroots engagement and progressive networking of the Initiative by creating an avenue for organizations and individuals in the community to regularly come together to discuss opportunities for collaboration. On the other side of the equation, language about economic development, innovation, and entrepreneurship appeal to the values of political and economic leaders in more conservative communities like West Fargo, ND. Strategic communication language was developed (see Figure 1). Perhaps the biggest challenge facing the members of the strategic communication subcommittee was determining how to intentionally integrate essential core concepts like equity, inclusivity, and diversity without triggering the polarization that increasingly accompanies these terms.

When it came time to implement the new plan, the issues of equity, diversity, and inclusion proved a persistent challenge. Three main approaches were taken in order to enhance youth and minority engagement in the CCFP (as the commissioners recommended in their interviews). First, the Cass Clay Food Partners Action Network was devel- 
Journal of Agriculture, Food Systems, and Community Development

ISSN: 2152-0801 online

https:/ / www.foodsystemsjournal.org

Figure 1. Strategic Communications Language for Cass Clay Food Partners

Tagline Building a strong, healthy, and vibrant food system.

Mission To improve all levels of our community food system to assure that residents have access to safe, nutritious, affordable, and culturally-based foods.

Vision All members of the community have access to safe, nutritious, affordable and culturally-based food.

Values: 1. We believe in an inclusive, integrated, and equitable food system.

2. We believe in a food system that is economically and ecologically resilient.

3. We believe in a food system where all cultures are respected.

4. We believe in a food system that supports and enhances quality of life for all citizens.

5. We believe in a food systems that fosters successful entrepreneurship and sustainable innovation.

Goals 1. To create an inclusive, well-connected food system.

2. To provide equitable access to safe, nutritious, affordable, and culturally appropriate food.

3. To create opportunities to achieve a healthy lifestyle and reduce the risk of chronic diseases.

4. To promote self-sufficiency through food-skills education and production opportunities.

5. To create a framework and structure that allow for shared leadership where all interested citizens can come together to achieve our goals.

Statement of Approach We approach the accomplishment of our stated goals and values by:

- Encouraging shared leadership throughout the Partners

- Engaging the citizens and key stakeholders of Cass and Clay counties to take action

- Fostering teamwork and shared responsibility

- Catalyzing systemic changes through food related policy and environmental approaches

Selected Key Messages

- Having easy, consistent access to healthy, affordable, and culturally based food can help people achieve a healthy lifestyle and prevent chronic diseases.

- Creating opportunities for people to grow and produce their own food allows people to become selfsufficient and live in resilient communities.

- Cass Clay Food Partners seeks to engage food system stakeholders and citizens to work together to develop a food system that is inclusive, well connected, and economically vibrant.

oped to serve as the conduit between grassroots organizations, the Commission, and the steering committee. The initial activity of the Action Network was First Friday, a monthly event that highlights food systems ideas and programs. The kickoff First Friday event featured G rowing Together, a food justice group that partners with immigrants and refugees. Second, the steering committee actively sought out the participation of an immigrant community member to serve as an at-large commissioner who was excited to join, rather than falling back on someone from the immigrant community who is always asked to lead. Third, an updated version of the Metropolitan Food System Plan included stronger language that prioritized inclusivity of minority and youth groups.
D espite these efforts, the current structure and culture of government is oriented toward the white dominant culture and creates an institutional barrier to progressive ideas of inclusivity. O ur network continues to examine how certain structures (meeting times and locations, percentage of professionals vs. lay people serving on the steering committee) reinforce our distance from minority groups and youth. Recent local elections have seen a surge in minorities running for positions on city councils, school boards, park boards, and as mayors. While we wait for the political system to change through the democratic process, prioritizing inclusivity in all facets of the organization's strategy is necessary to enfranchize underrepresented groups.

The CCFP vision and structure represent an 
integrated approach that weaves together the grassroots work of the previous Initiative, the policy work of the Commission, and the leadership of the steering committee, while also opening the door for more community involvement. The new look of the network was well received by Commission members and the community. There is great interest in the launch of the Action Network, with over 120 people attending the kickoff First Friday event, including municipal planners, local elected officials, and congressional staff from both states. Time will tell if the new structure of the network will generate greater support for local food system programs and policy.

\section{Moving Forward}

Though the latest iteration of the CCFP is new, there are many lessons to share from the evolution of this network since 2010 and our efforts to cross boundaries that have inhibited food systems work in the past. Inevitable tensions exist when working within a network, including divergent values and different preferences for processes, networking, or action (Schiff, 2008). Additional challenges occur when the work is disconnected (Sadler et al., 2015); for example, the project-based work of autonomous task forces of the Initiative diminished without an overarching strategy or vision to advance the work. In contrast to the disparate approach of the task forces, the formation of the Commission was a unifying approach, a place where the steering committee members could pool their energy and resources into advancing policy efforts by advising and partnering with local government entities, without spreading themselves too thin trying to maintain projects and consistent community engagement.

The irony of this shift was that the network was ultimately unable to advance policy work very far past the education and leadership development phases and was limited in building more public support and engagement. In fact, city and county planning staff indicated that organized efforts to set policy agendas are less influential than policymakers simply hearing from their constituents about an issue. The local government officials serving on the Commission have also indicated that they are uncertain as to where their constituents stand on food policy issues, pointing to the need for greater community engagement and grassroots advocacy efforts in tandem with the advisory and research-based role of the steering committee. O nce an issue is on their radar as something that the community cares about, then policy-makers need to know about the research and examples from other communities (Wegener et al., 2013). The formation of the CCFP is an attempt to bridge grassroots networking and project-based work with governmental policy efforts in a mutually reinforcing way.

Although food networks often focus on local issues and bridging grassroots efforts, they could readily expand to influencing state or federal policy (Sadler et al., 2015). Council effectiveness is defined as "synergy, or the power to combine resources and perspectives to create new approaches to complex problems" (Calancie, Allen, Weiner, Wen Ng, Ward, \& Ammerman, 2017, p. 2). The CCFP chose to focus its resources on local issues because of its late entry into food system planning work as compared to other areas of the country. Nonetheless, as members of the CCFP, we have connections to state and national partners. We believe these connections bridge local policymakers with broader efforts and simultaneously tailor the focus to a local political context, as recommended by Clayton, Frattaroli, Palmer, and Pollack (2015). The interplay between local governmental efforts and state-level influence was integral in the formation of the Commission and in lending credibility to the policy blueprints, which have been promoted through the Minnesota Food Charter Network and helped inform the development of the Food Access Planning Guide (Minnesota Food Charter, n.d.-a).

Before forming the CCFP, multiple organizational models were examined to determine the best fit for the local context. One such example, the Puget Sound Regional Council, also relied on a regional, metropolitan planning council, promoted best practices, distributed toolkits, and provided technical assistance to multiple jurisdictions. Nonetheless, the Puget Sound Regional Council has been less successful at promoting its guiding principles of equity and justice (Horst, 2017). Like the Puget Sound experience, the CCFP can look 
ahead to improving food security for vulnerable residents. However, we recognize that the focus will need to shift to employing mechanisms for soliciting feedback from diverse citizens and stakeholder types (Buchan, Cloutier, Freidman, \& O stry, 2015). Formats for receiving input could include diverse facilitators or "animators" who provide feedback and background information on key policy issues by drawing people into comfortable, informal settings like the CCFP Action Network (Ankeny, 2016, p. 16).

Having multiple governmental jurisdictions represented in the Cass Clay Food Commission creates tensions between competing interests, such as key policy differences between metropolitan and rural jurisdictions. Another tension exists around the expectation that grassroots changes must be accompanied by a business case emphasizing economic viability without government funding. In a conservative political climate such as ours, changes that include government spending or the creation of government jobs (even if those jobs are meant to enhance innovation and benefit the common good and/ or vulnerable populations) are often rejected. On the other hand, including multiple government jurisdictions with diverse stakeholders can also have the beneficial effect of bringing people together to learn about economically viable approaches.

O ther local governmental jurisdictions that face similar limitations caused by a conservative political climate should develop a multifaceted approach of long-term planning and methodical strategies. We recommend that they consider starting with small, highly visible projects to raise community awareness while consistently using multiple forms of media to spread awareness. Make sure local policymakers know about the successes so they are open to becoming engaged in the creation of a food policy council- with the assurance that the council is advisory only. Once the food policy council is created, focus on educating the members. After the food policy council members are educated and aware of various policy options, mobilize the community to support and encourage the policy-makers. In our community, policymakers rely on their constituents to drive change because they may not be innovative or brave about advancing new ideas, or are slowed by government inertia. Finally, be sure to include specific objectives around inclusivity and strategic communication. Disrupting entrenched power systems through diverse perspectives is a slow, trustbuilding process. Resist the temptation to tokenize existing leaders from minority groups and instead invest in building new relationships through oneon-one interactions and attending events in underserved neighborhoods.

\section{Conclusion}

We recognize that organizational, governmental, and individual self-interests are essential to hold networks together. Citizens, government agencies, and elected officials must see what they have to gain from being at the table in order to stay engaged in a network. The CCFP has demonstrated the value and challenges of shared leadership between local government agencies, nonprofit organizations, educators, and citizens by setting aside individual and organizational goals in order to stay focused on advancing the collective work. The inclusion of local government agencies including county commissions, city councils, and regional councils of governments is critical to the work of any food network and should be bolstered through increased feedback mechanisms between government and diverse community members. A "leaderful" framework that involves key actors such as farmers, food processors, underrepresented groups, community and educational groups, and state and federal agencies has also proven to be a powerful way to integrate food system issues into the social and physical fabric of communities. Moving forward, the CCFP will continue to serve as a model integrated food network that addresses the limited access to affordable, healthy, local food for residents who not too long ago lacked ready access to local food other than row crops like corn, soy, and sugar beets.

\section{Acknowledgments}

The authors would like to thank the Cass Clay Food Partners steering committee and the Cass Clay Food Commission for their work to increase food access and build a health food system across the region that they serve. 


\section{References}

Andreatta, S., Rhyne, M., \& D ery, N. (2008). Lessons learned from advocating CSAs for low-income and food insecure households. Southern Rural Sociology, 23, 116-148. Retrieved from http:/ / citeseerx.ist.psu.edu/ viewdoc/ download?doi=10.1.1.497.2143\&rep=rep1\&type=pdf

Ankeny, R. A. (2016). Inviting everyone to the table: Strategies for more effective and legitimate food policy via deliberative approaches. Journal of Social Philosophy, 47(1), 10-24. https:/ / doi.org/ 10.1111/ josp.12141

Buchan, R., Cloutier, D ., Freidman, A., \& O stry, A. (2015). Local food system planning: the problem, conceptual issues, and policy tools for local government planners. C anadian Journal of U rban Research, 24(1), 1-23. Retrieved from http:// www.jstor.org/ stable/ 26195275

Calancie, L., Allen, N. E., Weiner, B. J., Wen Ng, S., Ward, D. S., \& Ammerman, A. (2017). Food policy council selfassessment tool: D evelopment, testing, and results. Preventing Chronic D isease, 14. https:// doi.org/ 10.5888/ pcd14.160281

City of Fargo. (n.d.). Cass Clay Food Partners resources. Retrieved from http:/ / fargond.gov/ citygovernment/ departments/ fargo-cass-public-health/ nutrition-fitness/ cass-clay-food-partners/ resources

Clark, J. K., Freedgood, J., Irish, A., Hodgson, K., \& Raja, S. (2017). Fail to include, plan to exclude: Reflections on local governments' readiness for building equitable community food systems. Built E nvironment, 43(3), 315-327. https:/ / doi.org/ 10.2148/ benv.43.3.315

Clayton, M. L., Frattaroli, S., Palmer, A., \& Pollack, K. M. (2015). The role of partnerships in U.S. food policy council policy activities. PL OS ONE , 10(4). https:/ / doi.org/ 10.1371/ journal.pone.0122870

Colasanti, K., Wright, W., \& Reau, B. (2009). Extension, the land-grant mission, and civic agriculture: Cultivating change. Journal of Ex tension, 47(4), Article 4FEA1. Retrieved from https:/ / www.joe.org/ joe/ 2009august/ a1.php

Fargo-Moorhead Metropolitan Council of G overnments. (2013). M etropolitan food systems plan. Retrieved from http:/ / download.cityoffargo.com/ 0/metropolitan food systems plan final november 2013-1.pdf

Horst, M. (2017). Food justice and municipal government in the USA. Planning Theory \& Practiœ, 18(1), 51- 70. http:/ / dx.doi.org/ 10.1080/ 14649357.2016.1270351

Lyson, T. A. (2004). C ivic agriaulture: Reonnecting farm, food, and community. Medford, MA: Tufts University Press.

Minnesota Food Charter. (n.d.-a). Food Access Planning Guide. Retrieved from http:/ / mnfoodcharter.com/ planningguide/

Minnesota Food Charter. (n.d.-b). M innesota F ood C harter. Retrieved from http:/ / mnfoodcharter.com/ wpcontent/ uploads/ 2014/10/ MNFoodCharterSNG LFINAL.pdf

Pothukuchi, K., \& Kaufman, J. L. (1999). Placing the food system on the urban agenda: The role of municipal institutions in food systems planning. A grialture and $\mathrm{H}$ uman V alues, 16(2), 213-224. https:/ / doi.org/ 10.1023/ A:1007558805953

Sadler, R. C., Arku, G., \& G illiland, J. A. (2015). Local food networks as catalysts for food policy change to improve health and build the economy. L ocal E nvironment, 20(9), 1102-1121. https:/ / doi.org/ 10.1080/ 13549839.2014.894965

Schiff, R. (2008). The role of food policy councils in developing sustainable food systems. Journal of $H$ unger \& E nvironmental N utrition, 3(3), 206-228. https:/ / doi.org/ 10.1080/ 19320240802244017

Sonnino, R., Marsden, T., \& Moragues-Faus, A. (2016). Relationalities and convergences in food security narratives: Towards a place-based approach. Transactions of the Institute of British G eographers, 41(4), 477-489. https:/ / doi.org/ 10.1111/ tran.12137

Walker, R. E., Keane, C. R., \& Burke, J. G . (2010). D isparities and access to healthy food in the United States: A review of food deserts literature. H ealth \& Plaœ, 16, 876-884. https:/ / doi.org/ 10.1016/ j.healthplace.2010.04.013

Wegener, J., Seasons, M., \& Raine, K. D . (2013). Shifting from vision to reality: Perspectives on regional food policies and food system planning barriers at the local level. Canadian Journal of U rban Research, 22 (Suppl. 1), 93-112. Retrieved from http:/ / www.jstor.org/ stable/ 26193939 